\title{
Using Empirical Data To Build An Advisory Tool For Ecodesign
}

\author{
McAloone, Timothy Charles; Evans, S.
}

Published in:

Proceedings of the First International Symposium On Environmetnally Conscious Design And Inverse Manufacturing

Link to article, DOI:

10.1109/ECODIM.1999.747580

Publication date:

1999

Document Version

Publisher's PDF, also known as Version of record

Link back to DTU Orbit

Citation $(A P A)$ :

McAloone, T. C., \& Evans, S. (1999). Using Empirical Data To Build An Advisory Tool For Ecodesign. In Proceedings of the First International Symposium On Environmetnally Conscious Design And Inverse Manufacturing (pp. 52-55). IEEE Computer Society Press. https://doi.org/10.1109/ECODIM.1999.747580

\section{General rights}

Copyright and moral rights for the publications made accessible in the public portal are retained by the authors and/or other copyright owners and it is a condition of accessing publications that users recognise and abide by the legal requirements associated with these rights.

- Users may download and print one copy of any publication from the public portal for the purpose of private study or research.

- You may not further distribute the material or use it for any profit-making activity or commercial gain

- You may freely distribute the URL identifying the publication in the public portal 


\section{Using Empirical Data To Build An Advisory Tool For Eco-Design}

\author{
Dr. T.C. McAloone \\ Department of Control and Engineering \\ Design The Technical University of \\ Denmark \\ Building 358 \\ 2800-Lyngby, Denmark \\ tim@mcaloone.com
}

\author{
Prof. S. Evans \\ Eco-Innovations Group \\ Cranfield University \\ Cranfield \\ Bedfordshire \\ MK43 0AL, UK \\ steve.evans@cranfield.ac.uk
}

\begin{abstract}
Many product manufacturers are now implementing eco-design principles, albeit to varying degrees. It is these degrees of variance that were of particular interest in the research presented in this paper. Based on the hypothesis that there exists no single systematic approach to eco-design, which allows for the consideration of environmental issues in every stage of the product development process, an exploratory study sought to identify the various stages that companies travelled through when implementing eco-design principles. The electrical/electronics industry was the chosen subject for the study.
\end{abstract}

Results from this empirical research revealed that there is a common sequence of events that many companies go through when integrating eco-design into their product development processes, as presented in the model of eco-design integration in this paper. This sequence of events would be easily recognised by change management practitioners. Further to the common sequence of change in the companies, it was found that there were also common issues which companies aimed to improve when attempting to learn more about eco-design.

Plotting the model of eco-design integration against the common issues it was possible to develop a tool that was useful for industry, allowing companies to chart their progress in the eco-design issues of greatest concern to themselves. The 'eco-design advisor' presented here is the result of the development of the model into a tool.

\section{Introduction}

This research was predicated by the untested observation that eco-designing companies used an abundance of tools, often taking decisions in different stages of the design process in different ways, and often attacking different targets. The research set out to identify whether there was any commonality in this apparently non-systematic approach to eco-design.
An exploratory study was carried out in the electrical/electronics industry sector to chart the environmental practices during product development [1]. The aim of the exploratory study was to identify a common trend for the industry and to find out what the issues were when this sector of industry attempted to include environmental considerations into their designs and into their product development processes. An exploratory approach was used to investigate to what extent company practice followed the practice documented in literature, and whether any common patterns existed between different company implementations of eco-design.

\section{Research Method}

The research method adopted for this empirical study was selected to reflect the qualitative nature of the survey. One in-depth case study, where the authors followed a particular design project inside a company, acted as a pilot to generate the hypotheses for the study. These hypotheses were in turn tested by means of an industry survey, which entailed visiting practitioners in thirty-two companies from the electrical/electronics industry sector, covering Europe and North America.

A semi-structured interview technique was adopted for the industry survey and the data collected were qualitatively analysed. The semi-structured questionnaire that was used covered five main topics, targeted at gaining insight from industry. The topics, in brief, asked:

- what level and type of top management commitment was necessary for eco-design to be successful in the companies;

- in which way was eco-design built into existing company design methods, and what special changes were made for eco-design to become integrated;

- what importance did team-working play in the ecodesign process, and was it possible to define tasks 
that could be carried out alone and tasks that must be carried out in a team;

- what types of eco-design tools had been adopted by the companies, what did they look like, and at what stage of design were they used;

- what problems had been encountered when integrating eco-design principles into the product development process.

The analysis of the results from the industry survey allowed a picture to be built that represented the current way in which industry was addressing and integrating eco-design into their product development. Over one hundred practitioners were addressed in this survey.

\section{Results}

The analysis of the data from this survey led the authors to observe a chronological pattern in the way that industry was integrating environmental decisions into their product development. This chronology can be represented in a model of eco-design integration [1], as presented in Figure 1. The model represents the complex organisational changes that companies were observed to go through when integrating environmental criteria into their designs, by describing a three-stage process of change: initial/ sustained motivation; communication/information flow; and whole-life thinking, which are explained in greater detail below. The model in Figure 1 is the result of the industry survey, and is a progression from that presented in an earlier paper by the authors [2].

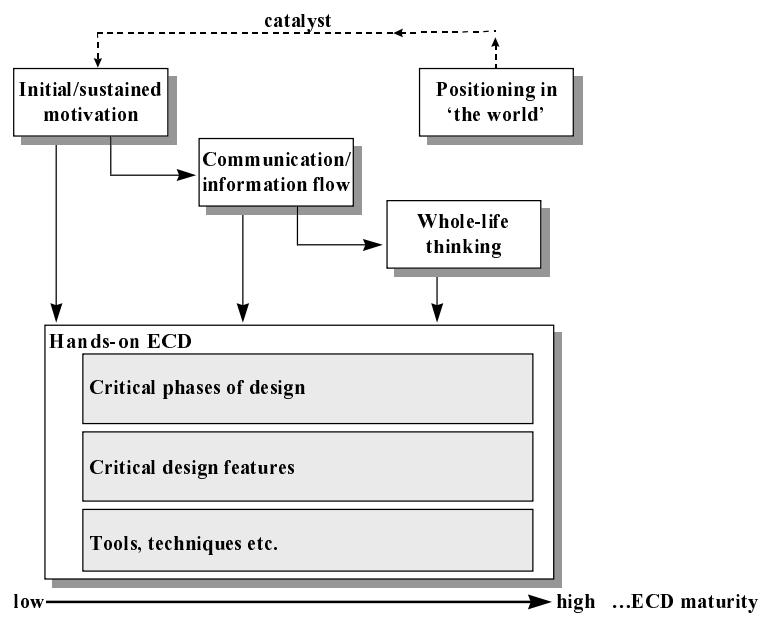

Figure 1 - A model of eco-design integration

The remainder of this section will discuss the model of eco-design integration in relation to the five categories described in Figure 1.

Considering firstly hands-on ECD, this category describes the physical 'doing' of eco-design. The three factors that make up this category decompose the act of practising eco-design into:

- timing - the scheduling of eco-design decisions and actions;

- product - the desired environmental features of the product; and

- tools - the tools and techniques used to achieve the features.

The last two factors are growing areas of research and there is an evolving catalogue of examples of environmental product features and of eco-design tools and techniques [3]. The first factor emphasises the sound scheduling of environment-related design decisions, and particularly the need to make many critical decisions before the specification is fixed. If we view down through all three factors we can see that the importance of early decisions is mirrored in the product features in that many of them can still be altered at that stage of the product development process. However few tools were found which mapped to this and this suggests an area which needs further research. (This topic has been taken up for further discussion in a companion publication [4]).

The top part of the model explains the common phases of eco-design maturity that companies were observed to pass through. In the first stage of eco-design integration (initial/sustained motivation), the companies were observed to be reacting to a single external demand or force, such as CFC legislation or a competitor product. Initial motivation was sometimes observed to be entirely within the design process, with little management contact. Progress from a single design project which successfully dealt with a single issue/feature to sustained motivation, was said to require significant top management commitment, unlike the initial motivation which was a reactive posture. However only after top management understanding and then commitment was gained did companies consider themselves to have achieved sustained motivation.

The next stage of eco-design integration was observed to be communication/information flow. This stage was only achieved when more than one of the factors in the category of initial/sustained motivation were active within the company, and with the necessary ingredient of top management commitment. (It was also observed that some had not yet managed to leave the reactive stage of initial/sustained motivation.) The companies which reached this stage of eco-design integration had begun to gain momentum towards the practice of ecodesign. This stage was characterised by use of ecodesign in multiple projects, by increasingly wider 
involvement of departments into the eco-design process, and by an introduction of some organisational learning about eco-design principles (be it in the form of education of the workforce, membership of design reviews, environmental workshops and training sessions, or the provision of specific information on topics such as hazardous materials).

This second stage of eco-design integration is where the majority of the companies interviewed were seen to be. During this phase the concept of eco-design transformed from a single issue, such as dissassemblability, and caused more and more features to come into consideration. However, the more advanced companies in this category had begun to recognise the life-cycle effects of their decisions, and that choosing environmentally superior 'material $\mathrm{x}$ ' in the materials selection phase does not just stop there - it has knock-on effects throughout the rest of the product's life-cycle. Indeed, by choosing the 'best' material from an environmental perspective, the overall environmental affect of the product may even have been worsened. At this stage, designers stated that they could no longer use simple tools and techniques, as they were suddenly having to consider many different lifecycle stages and many different stakeholders all at once. In this category, the company is improving its knowledge of eco-design, often by drawing upon the knowledge already available from its own personnel, and thereby improving its eco-design maturity (as is depicted by the notional low $\rightarrow$ high 'ECD maturity' scale at the bottom of Figure 1).

The final stage of eco-design integration (whole-life thinking) describes the few companies who were seen to be ahead of the majority, and had developed a high understanding of the trade-offs available between different product life-cycle phases. An initial realisation in this category was that ecological improvements could also mean economical benefits for the company. This often led to an adjustment in the view of what constituted core-business for the company, from focusing on product development and manufacture to service provision. It was claimed by the companies that this change in philosophy enabled them to take the view that their products were assets which should be fostered even after they had been sold to the customer.

Whole-life thinking is not perfection, however. To fully realise this excellent capability a performance focus is needed, which continually seeks the next benchmark or the next tool or the next product feature and incorporates them into their own goals and plans. For example, one company seeking to remove all fire retardants where no legislation enforced this; or another company involving design management in planning for future disassembly plants. This category seems to stand out on its own and was termed positioning in 'the world', as companies were observed to use external awareness, company goals and benchmarks as a constant encouragement to eco-design activity.

Figure 1 represents a relationship between the elements of a physical design process ('hands-on ECD') and the elements of a change process (the categories that describe the steps towards an improved physical design process). Although the research questions were targeted at both the physical design process and the process of change towards eco-design, the data have emphasised the process of change as being of greater concern to practitioners.

\section{Developing The Model Into A Tool}

As researchers we aim to understand the world, in this case the world of eco-design. As engineers we like to solve problems, to improve the current situation. As engineering researchers we can hopefully do both by ensuring the results of our research are made available to industry in an easily accessible way and by observing the use of the results.

As part of this form of action research the authors have developed the model into a tool. Being a model of ecodesign implementation the potential tool users have been specified as being those involved in deciding how a company should implement eco-design. Often this is a small, ad-hoc group (especially in the earliest stages); later the group may grow and become more formally part of the company planning process. Typical members include design management, design tool providers, design process owners and sometimes design manual owners.

The prime use of the tool is as an aid to understanding the company position, when compared to other companies. The tool should not give specific advice on a course of action but should suggest what important things may need to be considered. The research data showed that no absolute single pattern of implementation was correct. Some companies advanced their use of tools considerably before realising the need to become involved in the earlier stages of design. Other companies kept the initiative part of the design department for an extended period before involving others. Neither were wrong - and typically they were correct in choosing a style of implementation that suited the company ("we like computer tools, therefore a tool dominated approach is very comfortable for us'). 
The format of the tool is important in giving the impression of being advisory or being prescriptive; in being easy to use by a group; and in showing and giving an impression of progress. The chosen format is shown in Figure 2. The eco-design advisor is a set of questions that can be answered by individuals or groups; the answers are then plotted onto the arrow and shaded to show progress.

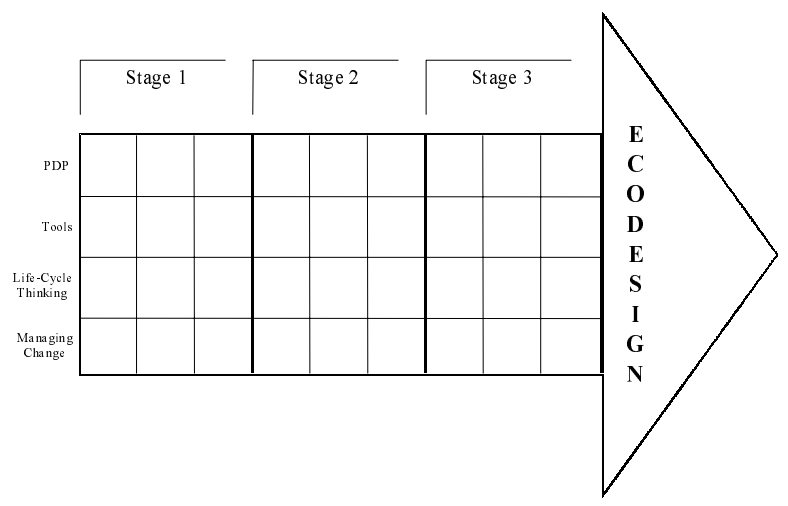

Figure 2 - The eco-design advisor

Each strand is linked to the model, e.g. 'Tools' asks questions about use of Life Cycle Analysis and Design Manuals. The questions which are answered 'yes' are shaded and the general progression of answers maps onto the typical implementation pattern observed in the companies. Hence, 'Do you have environmental criteria in your gate reviews?' maps onto Stage 1, as many companies do this early in their eco-design implementation. 'Do you discuss product environmental requirements prior to drawing up your specification?' maps onto Stage 3, as this was only observed in advanced eco-design practitioners.

The format allows for various modes of use: if individuals separately describe the current situation and then align their plots it can help to identify variation in perception of 'where we are today'. If the more mature stages of eco-design are shaded but the earlier stages are not, this should encourage a debate on whether the issue is important to the company and should be dealt with to provide a sound basis to proceed. If one strand, such as 'Tools', is shaded in most boxes but another is lacking, then this should raise a debate on the balance of the implementation (e.g. 'are we too tool-oriented?').

\section{Conclusions}

It was observed that, indeed, no single way to conduct the eco-design process was found. Each company tackled the design process in their own way, combining tools, targets, teaming, decision timing, etc. uniquely. However, a common pattern for the implementation of eco-design was observed. The model described the prime components as three stages of maturity and how these changed the use of tools, which features were targeted and what phase of design was used to achieve the target.

Using these results an eco-design advisor tool was developed, which companies may use to map their own implementations. While not being prescriptive, the tool does allow companies to compare their actual position with those companies who have gone before. The outcome of using the tool is hopefully a better understanding of eco-design implementation and some possible next steps for a company. This should then be integrated into the companies' own planning process.

The authors have been and will continue to use the tool to collect observations from other users, leading to a continuously improved advisory tool and improved understanding of the implementation planning process.

\section{References}

\section{Acknowledgements}

This research was conducted simultaneously with the DEEDS project and the authors would like to recognise the important role that Dr. Tracy Bhamra, Dr. Matthew Simon and Mr. Andrew Sweatman played, as well as the benefit of funding from the Engineering and Physical Sciences Research Council, ICL UK Ltd. and Electrolux Floorcare UK Ltd.

[1] T. C. McAloone, "Industry Experiences Of Environmentally Conscious Design Integration: An Exploratory Study," in The CIM Institute. Cranfield: Cranfield University, 1998, pp. 180.

[2] T. C. McAloone and S. Evans, "How Good Is Your Environmental Design Process? A Self Assessment Technique," Proceedings of International Conference of Engineering Design: ICED '97, Tampere, Finland, 1997.

[3] A. S. Sweatman, S., "Design For Environment Tools And Product Innovation," presented at CIRP 3rd International Seminar on Life-Cycle Engineering, 'Eco-Performance '96', Zurich, Switzerland, 1996.

[4] M. Simon, S. Evans, T. C. McAloone, A. Sweatman, T. Bhamra, and S. Poole, Ecodesign Navigator. Cranfield: Manchester Metropolitan University \& Cranfield University, 1998. 